\title{
Uma perspectiva comparada entre Friedrich Nietzsche e Fernando Pessoa: o filósofo poeta e o poeta filósofo
}

\author{
A comparative perspective between Friedrich Nietzsche and Fernando \\ Pessoa: the poet philosopher and the philosopher poet
}

\author{
João Francisco Pereira Nunes Junqueira \\ Professor Mestre do Centro Universitário Teresa D'Ávila, Lorena, SP, Brasil. \\ jfpnjunqueira@yahoo.com.br-https://orcid.org/0000-0002-1079-8605 \\ Thales Vinicius Rodrigues Pinto \\ Graduado no Centro Universitário Teresa D'Ávila, Lorena, SP, Brasil. \\ thalesrodrigues060@gmail.com - https://orcid.org/0000-0002-8642-5258
}

\begin{abstract}
RESUMO: Friedrich Wilhelm Nietzsche (1844-1900) e Fernando Pessoa (1888-1935) ocuparam-se das principais temáticas de suas épocas, sendo o primeiro um dos filósofos mais estudado na contemporaneidade e Pessoa considerado o maior poeta da Língua Portuguesa. Na comparação de algumas abordagens dos pensadores surgem semelhanças em temas específicos: o tratamento ao corpo, a questão da linguagem (amplamente estudada e colocada no centro das discussões epistemológicas de suas respectivas épocas), o tempo e a problemática do Ego. Objetiva-se, então, apresentar algumas semelhanças entre os dois pensadores, considerando cada um em sua maneira particular de expressão para, adiante, relacioná-las. No curso da comparação, são apresentadas as ideias consideradas mais convergentes, presentes em trechos dos próprios autores, assim como em análises realizadas por comentadores como Scarlett Marton e José Augusto Seabra. Importa levar em conta que mesmo Nietzsche sendo filósofo, este também escreve poesias e introduz em seus textos filosóficos elementos poéticos, da mesma maneira, Fernando Pessoa não deixa de registrar em seus versos a influência da filosofia. É a partir destas concepções que se pretende registrar os pontos de consubstanciação de uma obra com a outra. É possível concluir, portanto, que a comparação entre Nietzsche e Pessoa apresentou-se como um terreno profícuo, sendo possível, inclusive, realizar futuros avanços comparativos das obras.
\end{abstract}

Palavras-chave: Friedrich Nietzsche; Fernando Pessoa; Filosofia; Poesia; Linguagem.

ABSTRACT: Friedrich Wilhelm Nietzsche (1844-1900) and Fernando Pessoa (1888-1935) dealt with the main themes of their times, the first being one of the most studied philosophers in contemporary times and Pessoa considered the greatest poet of the Portuguese language. In the comparison of some approaches of the thinkers, similarities emerge in specific themes: the treatment to the body, the question of language (widely studied and placed at the center of the epistemological discussions of their respective times), the time and the problematic of the Ego. The objective here is to list some similarities between the two thinkers, considering each one in their particular way of expression and, from that point on, to highlight possible similarities between both. It is important to take into account that even though Nietzsche is a philosopher, he also writes poetry and introduces poetic elements in his philosophical texts, in the same way, Fernando 
Pessoa does not fail to register the influence of philosophy in his verses. It is from these conceptions that we intend to register the points of consubstantiation of one work with the other, even surpassing the first intention of pure comparison.

Keywords: Friedrich Nietzsche; Fernando Pessoa; Philosophy; Poetry, Language.

\section{O corpo anti-idealista}

No cerne da filosofia nietzscheana encontra-se sua total repulsa por qualquer sistema religioso de pensamento. Cita-se isso, pois, é a partir desta concepção que Nietzsche dá ao corpo um tratamento especial, tendo em vista que, no catolicismo (sistema religioso que Nietzsche dirige suas críticas mais severas), o corpo deve ser, em certos aspectos, negado em prol do desenvolvimento espiritual e da salvação da alma. Salienta-se ainda que, em relação à temática do corpo, a obra nietzscheana aborda-a de maneira mais profunda e também com outras direções, sendo realizado, no artigo em questão, um recorte de uma abordagem que interessa a comparação com Fernando Pessoa.

É a partir deste combate ao sistema religioso de pensamento que Nietzsche busca a valorização e exaltação do corpo humano em relação ao que é puramente intelectual; em Fernando Pessoa não há este combate a nenhum sistema religioso de pensamento. No poeta, os sentidos e as sensações são exaltados e posicionados em primeiro plano (característica presente principalmente no heterônimo Alberto Caeiro), sendo o escritor amplamente conhecido como precursor do Sensacionismo.

Enquanto em Nietzsche o corpo é visto como um todo pensante e apto a encontrar uma possível verdade sobre a vida, Pessoa, com a voz de seu heterônimo Alberto Caeiro (e também de outros heterônimos, sendo aqui privilegiado Alberto Caeiro), foca nos sentidos e sensações particularizados, tendo em vista que "por sensação entende Caeiro a sensação das coisas tais como são, sem acrescentar quaisquer elementos do pensamento pessoal, convenção, sentimento ou qualquer outro lugar da alma" (PESSOA apud SEABRA, 1974, p. 91-92).

Essa recusa da intromissão do pensamento no testemunho dos sentidos gerados pela experiência corporal é também defendida por Nietzsche: "Sempre escrevi minhas 
obras com todo o meu corpo e minha vida: ignoro o que sejam problemas puramente espirituais" (NIETZSCHE apud MARTON, 2000, p.33).

Elencando o sobreaviso de ambos os pensadores sobre a possível má influência da racionalidade em relação à pureza dos sentidos, lê-se em Fernando Pessoa ou o poetadrama, obra de José Augusto Seabra que guiará este estudo nas análises pessoanas, que: "Caeiro apresenta-se, antes de mais, como o poeta das sensações extremes: 'A sensação é tudo (...) e o pensamento é uma doença'” (SEABRA, 1974, p. 91). Já em Nietzsche, em Ecce Homo, o filósofo registra que "a vida sobre as nádegas...é que é o verdadeiro pecado contra o santo espírito" (NIETZSCHE, 2017c, p. 14). Linha de raciocínio semelhante à expressa em outro trecho da mesma obra: "Sentar o menos possível; não acreditar em nenhum pensamento que não tenha nascido ao ar livre e em movimentação - quando também os músculos estiverem participando da festa" (NIETZSCHE, 2017c, p. 48).

Eis alguns exemplos de como o corpo é inserido na interpretação dos fenômenos da vida, em contrapartida a qualquer possível interpretação que utilize exclusivamente a racionalidade como ferramenta avaliativa da experiência humana.

Em Fernando Pessoa, como método de superação deste mal-entendido causado pela influência da racionalidade no testemunho dos sentidos, Seabra afirma que

só através da absorção do pensamento pelas sensações se pode realizar a sua identificação mútua: exterior às sensações, o pensamento é uma excrescência, se não um vírus corruptor, que chega por vezes a perturbar a saúde do poeta, pondo em causa sua objetividade. (SEABRA, 1974, p. 92).

Observa-se que a racionalidade surge como algo apto a extraviar uma possível interpretação pura da realidade, como uma barreira que acaba por impedir uma relação mais direta e, portanto, mais fiel da existência humana com a realidade, entendendo, pois, que a racionalidade surge como método de corrupção da realidade, interpretando-a como se a realidade é que devesse adaptar-se ao pensamento, e não o contrário. O recurso do filósofo e do poeta busca a exata inversão de tal método: silenciar o máximo possível a intervenção da racionalidade e permitir que os sentidos humanos se relacionem da 
maneira mais direta possível com a realidade. Tal recurso inverte a linha de pensamento amplamente defendida pelos racionalistas, que abordam os sentidos como corruptores da objetividade.

Sobre tal questão, Nietzsche considera que o testemunho dos sentidos foi desvirtuado pelos racionalistas, já que estes buscavam um princípio de permanência na natureza do mundo apto a validar a ideia de verdade absoluta, tão perseguida por tais filósofos. Sobre essa idolatria da permanência e a defesa da racionalidade como único método epistemológico possível, alerta-nos o pensador em Crepúsculo dos ídolos que, como resultado, surge nestes pensadores a necessidade de:

dizer não a tudo o que crê nos sentidos (...). E, sobretudo, fora com o corpo, essa deplorável 'idée fixe' dos sentidos! acometido de todos os erros da lógica, refutado, até mesmo impossível, embora insolente o bastante para portar-se como se fosse real! (NIETZSCHE, 2017b, p. 20)

Em outro ponto desta obra, em sua defesa dos sentidos, Nietzsche afirma que:

eles não mentem. O que fazemos do seu testemunho é que introduz a
mentira; por exemplo, a mentira da unidade, a mentira da materialidade, da
substância, da duração... A razão é a causa de falsificarmos o testemunho
dos sentidos. (NIETZSCHE, 2017b, p. 21)

Se em Pessoa a racionalidade extravia uma possibilidade de interpretação pura da realidade, Nietzsche posiciona-a exatamente como a corruptora desta, sendo que ambos posicionam os sentidos, e consequentemente o corpo, como possibilidade verossímil de uma epistemologia apta a melhor interpretar a experiência dos fenômenos.

Estas são algumas opiniões destes dois pensadores sobre a influência da intelectualidade em estado bruto sobre o testemunho dos sentidos: excrescência, vírus corruptor, razão como a causa de falsificarmos o testemunho dos sentidos. Eis os pontos de vistas condizentes sobre o tema do corpo presentes no pensamento de Nietzsche e de Fernando Pessoa.

Abordando exclusivamente o poeta, sua busca de superação deste posicionamento que privilegia a intelectualidade sobre os sentidos é exatamente uma das matérias primas 
de sua poesia. Em alguns poemas de seu heterônimo Alberto Caeiro o poeta apresenta integralmente sua defesa dos sentidos, como neste trecho de $O$ guardador de rebanhos (II, "O meu olhar é nítido como um girassol"):

Creio no mundo como um malmequer,
Porque o vejo. Mas não penso nele
Porque pensar é não compreender...
O Mundo não se fez para pensarmos nele
(Pensar é estar doente dos olhos)
Mas para olharmos para ele e para estarmos de acordo...

(PESSOA, 2015, p. 153)

Esse poema pode ser exemplificado como afirmação da negação da presença do pensamento na interpretação do mundo, da já citada substituição do pensamento pela sensação, como no verso "Porque o vejo. Mas não penso nele...". Não pensar, não meditar, apenas ver, sem a intromissão do pensamento: eis o convite que o poeta nos faz.

Em outro dos poemas mais consagrados deste O guardador de rebanhos (IX, "Sou um guardador de rebanhos") de Pessoa, lê-se:

\author{
Sou um guardador de Rebanhos. \\ O rebanho é os meus pensamentos \\ E os meus pensamentos são todos sensações. \\ Penso com os olhos e com os ouvidos \\ $\mathrm{E}$ com as mãos e os pés \\ E com o nariz e a boca. \\ Pensar uma flor é vê-la e cheirá-la \\ E comer um fruto é saber-lhe o sentido.
}

(PESSOA, 2015, p. 164)

Eis uma das matérias-primas da poesia de Fernando Pessoa elucidada no terceiro verso da primeira estrofe. Há também no último verso da estrofe citada a defesa de que uma atitude perante o "fruto" é mais importante para desvendar-lhe um possível sentido do que necessariamente pensar-se ou meditar-se sobre ele. 
Esta busca por outro caminho apto a interpretar a realidade, que nega o pensamento e posiciona no lugar os sentidos em seu estado bruto, é reforçada em um dos "Poemas inconjuntos" no momento em que até o próprio tempo e o espaço dão lugar às sensações:

Eu nunca passo para além da realidade imediata.

Para além da realidade imediata não há nada.

(PESSOA, 2015, p. 197)

Nesse poema, o tempo só é afirmado pela realidade imediata, ou seja, o próprio instante presente, além disto, em versos como "Sinto todo o meu corpo deitado da realidade, / Sei a verdade e sou feliz" (PESSOA, 2015, p. 164), do já citado O guardador de rebanhos, "IX", o corpo não deita em um lugar específico, deita-se na realidade, só assim é possível alcançar alguma verdade e com isso ser feliz, o que provoca uma antítese absoluta em relação ao pensamento racionalista.

\section{O limite da linguagem}

Outro ponto convergente das obras dos autores é o tratamento que ambos dão à linguagem. Aqui, leva-se em conta que a época vivida por ambos é exatamente a época em que a Linguagem é colocada no centro dos problemas epistemológicos, sendo que a suspeita em relação às possibilidades da linguagem de chegar ao conhecimento verdadeiro e inequívoco foram colocadas em xeque, e nisto tanto Nietzsche quanto Pessoa contribuíram para deixar ainda mais robusta essa desconfiança.

Abordando o poema dramático $O$ Marinheiro de Fernando Pessoa, obra interessante, pois foi composta antes da criação dos heterônimos, já se evidencia uma das questões que ocuparam a poética do escritor: "Entre mim e a minha voz abriu-se um abismo" (PESSOA, 2015, p.140). Logo em seguida, encontra-se um pequeno trecho que contém profundas marcas do tratamento que Pessoa dá à linguagem: 
Contáveis e eu tanto me distraía que ouvia o sentido das vossas palavras e o seu som separadamente. E parecia-me que vós, e a vossa voz, e o sentido do que dizíeis eram três entes diferentes, como três criaturas que falam e andam. (PESSOA, 2015, p. 140-141)

Não pode passar despercebido que quando o poeta diz que ouvia o "sentido de vossas palavras e o seu som separadamente", acaba por provocar no leitor mais atento uma consubstanciação entre este trecho e os conceitos de significante e significado saussurianos (SEABRA, 1974, p. 30). Mas o que importa tanto no primeiro trecho quanto no segundo é o distanciamento não só do sujeito em relação aos seus respectivos objetos como também o hiato presente entre o sujeito e a linguagem, sugerido pelo abismo citado pelo autor.

Este istmo entre o sujeito e sua própria linguagem é assinalado também por Nietzsche, quando, por exemplo, o autor afirma que:

Acreditamos saber algo das coisas mesmas, se falamos de árvores, cores, neve e flores, e no entanto não possuímos nada mais do que metáforas das coisas, que de nenhum modo correspondem às entidades de origem... (NIETZSCHE apud MARTON, 2000, p.193).

Eis o que sinteticamente o pensador acredita rigorosamente ser a essência da linguagem: metáforas. Isto talvez justifique outra de suas concepções sobre ela, a de que "afala, ao que parece, só foi inventada para o corte transversal, o mediano, o comunicativo. Com a fala já se vulgariza o faltante" (NIETZSCHE apud MARTON, 2000, p. 192). O que pode ser inferido de tal trecho é que Nietzsche entendia que o que se apresenta como realmente importante na existência humana resguarda-se de ser expresso pela linguagem.

Já do poeta, elencar-se-á aqui trechos de dois poemas d'O guardador de rebanhos que dialogam diretamente com os trechos citados de Nietzsche. O primeiro deles ("Num dia excessivamente nítido", XLVII) diz:

Vi que não há Natureza,

Que natureza não existe,

Que há montes, vales, planícies, 
Que há árvores, flores, ervas,

Que há rios e pedras,

Mas que não há um todo a que isso pertença,

Que um conjunto real e verdadeiro

É uma doença de nossas ideias

(PESSOA, 2015, p. 183-184)

Nota-se como a palavra "Natureza" perde sua força expressiva, como ela deixa de significar o que comumente a ela se atribui, que chega a ser uma "doença" a crença em sua capacidade sintética. Este primeiro poema aqui citado dialoga diretamente com um segundo (“Só a Natureza é divina, e ela não é divina...”, XXVII):

\footnotetext{
Se falo dela como de um ente

É que para falar dela preciso usar da linguagem dos homens Que dá personalidade às cousas,

E impõe nome às cousas.

Mas as cousas não têm nome nem personalidade

$[\ldots]$

(PESSOA, 2015, p. 172)
}

Aqui o eu lírico toma a linguagem como seu próprio objeto, num exercício metalinguístico que primeiro afirma a necessidade de se utilizar a linguagem dos homens e depois nega suas possibilidades afirmando que as coisas não têm nome nem personalidade. Sobre este tratamento dado à linguagem, registra-se que "aqui aflora outro dos elementos da teoria do conhecimento poético de Caeiro: a obsessão do nominalismo" (SEABRA, 1974, p. 94).

E assim é categorizada a relação do heterônimo Alberto Caeiro com a linguagem: uma obsessão, que por vezes se apresenta como uma tentativa de superar o hiato existente entre o pensamento que estaria ainda numa espécie de estado bruto, ou seja, não-linguagem: 
Procuro dizer o que sinto

Sem pensar em que o sinto.

Procuro encostar as palavras à ideia

E não precisar dum corredor

Do pensamento para as palavras.

(PESSOA apud SEABRA, 1974, p. 103)

Superar o abismo e encostar as palavras à ideia, esta seria a citada obsessão de Caeiro em sua criação poética, realizar uma consubstanciação entre as palavras e a ideia, tarefa que, sendo impossível, resulta na descrença do heterônimo em relação às possibilidades expressivas da linguagem.

Retomando Nietzsche, há no filósofo uma passagem que registra o sentimento de impossibilidade expressiva da linguagem e sua incompletude, sentimento também experimentado por Pessoa:

O que é a verdade, portanto? Um batalhão móvel de metáforas, metonímias, antropomorfismos, enfim, uma soma de relações humanas, que foram enfatizadas poética e retoricamente, transpostas, enfeitadas, e que, após longo uso, parecem a um povo sólidas, canônicas e obrigatórias: as verdades são ilusões, das quais se esqueceu que o são, metáforas que se tornaram gastas e sem força sensível, moedas que perderam sua efígie e agora só entram em consideração como metal, não mais como moedas. (NIETZSCHE apud MARTON, 2000, p. 207-208)

Valer lembrar aqui do tema dos sentidos, explorado por ambos os pensadores, sobre o qual Nietzsche registra n'A Gaia Ciência que

o homem, como toda criatura viva, pensa continuamente, mas não sabe disso; o pensamento que se torna consciente é apenas a mínima parte dele, e nós dizemos: a parte mais superficial, a parte pior: - pois somente esse pensamento consciente ocorre em palavras, isto é, em signos de comunicação (...) Acrescenta-se que não é somente a linguagem que serve de ponte entre homem e homem, mas também o olhar, o toque, o gesto... (NIETZSCHE, 2017a, p. 227, aforismo 354)

Para finalizar essa passagem sobre o tratamento dado à linguagem pelos pensadores, cita-se outro poema de Fernando Pessoa: 


\begin{abstract}
Do eterno erro na eterna viagem
O mais que (exprime) na alma que ousa

É sempre nome, sempre linguagem

O véu e a capa de uma outra cousa.
\end{abstract}

(PESSOA apud SEABRA, 1974, p. 38)

Chama atenção o desvio assinalado pelo autor, que diz ser sempre "outra cousa" o que de fato significam as palavras, como se estas funcionassem como um "véu" ou "capa", ou seja, encobrem o que de fato é a coisa em si, cortinas empregadas por necessidade que não permitem que se veja propriamente a vida em seu estado natural.

\title{
Ode ao instante
}

Um dos conceitos mais discutidos na filosofia contemporânea é o Eterno Retorno nietzscheano. Complexo, tal conceito ocupa o centro de sua filosofia, funcionando como um verdadeiro medidor de qualidade direcionado para todos os fenômenos da existência humana, separando aquilo que merece ser vivenciado ou não.

Para exemplificar, imagine-se aplicando o conceito de Eterno Retorno sobre uma decisão qualquer de sua vida, a pergunta que deveria ser feita é: eu poderia fazer o que estou fazendo agora por toda a eternidade sem receio de que eu vá me arrepender disto? Se a resposta for sim, então você deve decidir-se por isso e não mais abandonar tal causa, se a resposta for não, você deve continuar perseguindo aquilo que você desejaria fazer por toda a eternidade sem receio de que haja remorso no meio do caminho.

Esta seria uma forma de adotar o conceito particularmente, mas este funciona ainda de maneira cosmológica, e sobre isso Nietzsche afirma que

\footnotetext{
se o mundo pode ser pensado como grandeza determinada de força e como número determinado de centro de força (...), disso segue que ele tem de passar por um número calculável de combinações, no grande jogo de dados de sua existência. Em um tempo infinito, cada combinação estaria alguma vez alcançada; mais ainda: estaria alcançada infinitas vezes. (NIETZSCHE apud MARTON, 2000, p. 183).
} 
Trata-se de algo como imaginar as infinitas possibilidades de combinações presentes na tabela periódica: num período de tempo infinito, tais combinações, mesmo com a quantidade incalculável de possibilidades existentes, acabariam se repetindo em algum momento.

Como resultado desta doutrina, o filósofo sugere que seus leitores vivam exclusivamente vinculados ao presente, ao instante. Ainda sobre o Eterno Retorno, devese ter em vista que tal conceito aborda tanto a cosmologia quanto o cotidiano existencial humano, age tanto sobre os fatos universais quanto os mais particulares possíveis de nossa realidade enquanto viventes.

Fernando Pessoa, através de alguns poemas, expressa de maneira similar seu tratamento à questão do tempo, por exemplo nestes dois versos de Alberto Caeiro:

Isto é o que hoje é,

E, como hoje por enquanto é tudo, isto é tudo.

(PESSOA apud SEABRA, 1974, p. 97)

A exaltação do presente é aqui ainda contida, apenas registrada; em outro momento, em versos já citados, ela é posicionada como o alicerce da negação da existência tanto do passado quanto do futuro:

Eu nunca passo para além da realidade imediata.

Para além da realidade imediata não há nada

(PESSOA, 2015, p. 197)

Voltando ao filósofo, há uma passagem em Crepúsculo dos ídolos que está presente esta mesma afirmação sobre o valor do presente em relação aos outros possíveis tempos (passado e futuro): "Não cometamos covardia em relação aos nossos atos! Não os abandonemos depois de fazê-los! É indecente o remorso!" (NIETZSCHE, 2017 b p. 9). Esse pensamento vai diretamente ao encontro da sabedoria poética expressa nestes outros versos d'O guardador de rebanhos ("Antes do voo da ave, que passa e não deixa rasto", XLIII): 


\begin{abstract}
A recordação é uma traição à Natureza,
Porque a Natureza de ontem não é Natureza.

O que foi não é nada, e lembrar é não ver.
\end{abstract}

(PESSOA, 2015, p. 181)

Presencia-se a exaltação, a ode dedicada ao presente, a negação do passado e a desconfiança em relação ao futuro. Em suas formas de tratar o tempo, surge tal concordância entre os pensadores: a de que só é possível existir, e mais, que só existe o agora.

\title{
A dissolução do Ego
}

Uma das questões que ambos os pensadores mais se debruçam é a da natureza do $E u$, questão problematizada tanto por Nietzsche quanto por Fernando Pessoa. Nomeado por Scarlett Marton como o filósofo da suspeita, Nietzsche desconfia seriamente da existência de um Eu como tradicionalmente considerou-se tal questão. É ainda a partir desta desconfiança do Eu que é feita uma comparação ao conceito de inconsciente, estipulado por Sigmund Freud. Para Nietzsche existiria algo pensante nos homens, independente e autônomo, que geraria no filósofo a desconfiança de que não somos senhores de nossa própria casa (nossa mente). Em um aforismo, o filósofo assinala que "nosso corpo nada mais é do que um edifício coletivo de várias almas" (NIETZSCHE apud MARTON, 2000, p. 187), concepção que pode ser diretamente aplicada ao processo heteronímico de Fernando Pessoa.

No poeta, tal problemática ocupa, de fato, parte significativa de sua criação poética, sendo inclusive a gestora dos heterônimos. Se em Nietzsche há uma desconfiança de que o nosso pensamento que se torna consciente é apenas um recorte deste algo que em nós pensa, muito maior e mais complexo, em Pessoa este algo revelar-se-á como múltiplo, multifacetado e dramático. Sobre isto pode ler-se que: "Nesta proliferação do eu numa multiplicidade de 'não-eus', implicando a concepção de um 'eu-postiço', reside todo o processo de criação heteronímica." (SEABRA, 1974, p. 5). Além de múltiplos, esses "nãoeus" que deságuam num "eu postiço" habitam o poeta não de maneira passiva, cada um 
ocupando um espaço independente e alheios uns aos outros, mas interagem, dialogam e criticam uns aos outros, num jogo de escrita-leitura que registra uma das marcas da obra pessoana. Por fim, afirma-se que "no próprio ato de escrever, o poema aparece ao poeta como outro (de outrem) e como tal lido pelo seu autor enquanto texto exterior a um sujeito poético ele mesmo descentrado" (SEABRA, 1974, p. 6).

Nos dizeres do próprio poeta: "o sujeito ao ser pensado como sujeito é objeto?" (PESSOA apud SEABRA, 1974, p. 64). Tratar o "sujeito" como "objeto", eis uma síntese do tratamento dado tanto pelo filósofo como pelo poeta, dissolvendo a separação existente entre sujeito e objeto e voltando os olhos às (im)possibilidades de sua natureza.

Sobre o tratamento à temática da desconfiança e a descrença da existência pura de um Ego, Nietzsche chega a exaltar-se nesta passagem de Crepúsculo dos ídolos: "E quanto ao eu! Tornou-se uma fábula, uma ficção, um jogo de palavras: cessou inteiramente de pensar, de sentir e de querer!..." (NIETZSCHE, 2017b, p. 34). Já em Fernando Pessoa, sua poética evidencia claramente sua problemática com um Ego definido e unificado, como se pode ver em um trecho de seu poema "Episódios/A múmia":

III

De quem é o olhar

Que espreita por meus olhos?

Quando penso que vejo,

Quem continua vendo

Enquanto estou pensando?

Por que caminhos seguem,

Não os meus tristes passos,

Mas a realidade

De eu ter passos comigo?

Às vezes, na penumbra

Do meu quarto, quando eu

Para mim próprio mesmo

Em alma mal existo,

Toma um outro sentido

Em mim o Universo -

É uma nódoa esbatida

De eu ser consciente sobre

Minha ideia das coisas.

(PESSOA, 2015, p. 107) 
A problemática sobre quem habita sua própria existência, expressa na primeira estrofe, não chega a ser solucionada no decorrer do poema, permanecendo sempre a questão inicial "De quem é o olhar / Que espreita por meus olhos?", questão insolúvel que simplesmente resulta numa "nódoa esbatida", que é propriamente a estranheza de "ser consciente sobre / Minha ideia das coisas".

Ainda sobre a multiplicidade de poetas num só, o próprio autor avisa que:

Não há que buscar em quaisquer deles ideais ou sentimentos meus, pois muitos deles exprimem ideias que não aceito, sentimentos que nunca tive. Há simplesmente que os ler como estão, que é aliás como se deve ler. (PESSOA apud SEABRA, 1974, p. XIV)

Ressalta-se que na obra nietzscheana, o filósofo assinala uma das consequências gerada pela dissolução da concepção tradicional do Ego, que seria perceber o absurdo do ser frente à consciência da verdade, da mesma forma este absurdo do ser é assinalado também na obra pessoana:

\footnotetext{
Mais que a existência

É um mistério o existir, o ser, o haver

Um ser, uma existência, um existir -

Um qualquer, que não este, por ser este -

Este é o problema que perturba mais.

O que é existir - não nós ou o mundo -

Mas existir em si?
}

(PESSOA apud SEABRA, 1974, p. 44)

O "problema que perturba mais" o poeta não chega a dissolver-se, mantém-se firme e hermético em toda sua obra.

Por fim, retomando a questão de um algo autônomo, registrado por Nietzsche, seguem outros versos da obra pessoana com esta perspectiva:

Não meu, não meu é quanto escrevo.

A quem o devo?

(PESSOA apud SEABRA, 1974, p. 6) 


\begin{abstract}
Vou escrevendo meus versos sem querer,
Como se escrever não fosse uma cousa feita de gestos,

Como se escrever fosse uma cousa que me acontecesse

Como dar-me o sol de fora
\end{abstract}

(PESSOA, 2015, p. 182)

Eu, que tantas vezes me sinto tão real quanto uma metáfora.

(PESSOA, 2015, p. 271)

Seremos nós canetas com tinta

Com que alguém escreve a valer o que nós aqui traçamos?

(PESSOA apud SEABRA, 1974, p. 6)

Eis como é tratada a questão do Ego e como ambos os pensadores dissolvem-na na desconfiança filosófica e na criação poética, questões que contemporaneamente podem ser abordadas com exagero ou repulsa.

\title{
Considerações finais
}

As obras de Friedrich Nietzsche e Fernando Pessoa podem ser estudadas como bússolas norteadoras de nossa contemporaneidade, seja para concordar seja para discordar de suas concepções de mundo. Compará-las abre parâmetro para que possa ser analisado, em poesia, aquilo que o filósofo expressou filosoficamente, porém sem deixar de introduzir em seus aforismos características poéticas, assim como Fernando Pessoa introduziu a filosofia em sua poesia, chegando a dizer inclusive que é um poeta animado pela filosofia.

Em relação aos resultados da pesquisa, registra-se que as quatro linhas comparativas (corpo, linguagem, instante e ego) podem ser entendidas como pedras de toque aptas à comparação dos autores em questão, tendo em vista que, no que diz respeito especificamente à questão da linguagem, tal temática é muito mais extensa e cara à filosofia, por isso a impossibilidade de abordar de maneira longa e detalhada o tema, sendo realizado, portanto, um recorte direcionado aos objetivos do artigo em questão. 
Além dessa questão específica, salienta-se que o artigo apresenta-se como uma possibilidade de abertura para um trabalho mais longo e detalhado sobre os quatro eixos aqui escolhidos, registrando, ainda, a pertinência e a proficuidade dos pontos comparados.

\section{Referências}

MARTON, Scarlett. Nietzsche: das forças cósmicas aos valores humanos. $2^{\underline{a}}$ ed. Belo Horizonte: UFMG, 2000.

NIETZSCHE, Friedrich. A gaia ciência. Tradução Antonio Carlos Braga. São Paulo: Lafonte, 2017a.

NIETZSCHE, Friedrich. Crepúsculo dos Ídolos ou Como se filosofa com o martelo. Tradução, notas e posfácio de Paulo César de Souza. São Paulo: Companhia de Bolso, 2017b.

NIETZSCHE, Friedrich. Ecce Homo: De como a gente se torna o que a gente é. Tradução, organização e notas de Marcelo Backes._Porto Alegre: L\&PM POCKET, 2017c.

PESSOA, Fernando. O eu profundo e os outros eus: Fernando Pessoa. Seleção Afrânio Coutinho. - [Ed. especial] - Rio de Janeiro: Nova Fronteira, 2015.

SEABRA, José Augusto. Fernando Pessoa ou o Poetodrama. São Paulo: Perspectiva, 1974.

\section{(c) (1) (8)(2)}

This work is licensed under a Creative Commons Attribution-NonCommercial 4.0 International (CC BY-NC 4.0) 